\title{
Seismic monitoring of Campi Flegrei and Vesuvius by stand-alone instruments
}

\author{
Mario La Rocca*, Danilo Galluzzo
}

Istituto Nazionale di Geofisica e Vulcanologia, Sezione di Napoli, Osservatorio Vesuviano, Naples, Italy

\author{
Article history \\ Received February 10, 2015; accepted September 8, 2015. \\ Subject classification: \\ Campi Flegrei, Vesuvius, Seismic array, Stand-alone seismic station, Seismic monitoring.
}

\begin{abstract}
A seismic network of more than 20 broad band stations and two arrays of 10 short period stations each, all working in local acquisition mode, are used to improve the seismic monitoring of Campi Flegrei and Vesuvius for research purposes. Data provided by stand-alone instruments are characterized by high quality and very continuous data streams, therefore they are appropriate to detect and analyze any seismic signals possibly related with the volcanic activity. Array data are particularly useful to discover and analyze seismic events characterized by low amplitude, low signal to noise ratio and emergent onset, but whose signals are more coherent among the array stations than the background noise. Since the background seismic signal is very high at both volcanoes, particularly at Campi Flegrei, seismic arrays and dense station networks are necessary to discriminate volcanic events from the many transient signals produced by artificial sources. In Campi Flegrei area the analysis with array methods of data recorded by ARF array permitted the discovery of low amplitude volcanic tremor of hydrothermal origin occurred in January 2015, a seismic signal never observed before in the area. At Mt. Vesuvius the analysis of VAS array data has shown the occasional occurrence of short bursts of low amplitude volcanic tremor. Small low-frequency earthquakes have also been revealed in the two volcanic areas.
\end{abstract}

\section{Introduction}

Seismic monitoring of active volcanoes is generally important for scientific purposes. If the volcano is surrounded by highly populated area its monitoring is even more important for the mitigation of volcanic hazard. Campi Flegrei caldera and Mt. Vesuvius are among the highest risk volcanoes in the world, therefore their monitoring has attracted great attention during the past decades. Seismic monitoring with modern instruments begun in early 1970, and developed continuously to ensure an up to date system for real time surveillance [Castellano et al. 2002, Orazi et al. 2013].

An increase of seismic activity with the occurrence of volcanic tremor and earthquakes of volcanic origin like low-frequency (LF) and long-period (LP) events is the most common precursor of volcanic eruptions [Chouet 1996, Konstantinou and Schlindwein 2002, Chouet 2003, McNutt 2005, Chouet and Matoza 2013]. Therefore identify and analyze such kind of events is an important effort to forecast the volcanic activity and reduce the volcanic hazard. However, the automatic detection of LF, LP, and tremor signals is quite difficult because usually they have emergent onset and low amplitude. In the case of Campi Flegrei and Mt. Vesuvius this task is even more difficult because the background noise is very high, with a lot of transient signals produced by artificial sources. Discriminating between artificial and natural sources in some cases is not obvious, while identifying volcanic tremor in the background signal may be a challenging task for seismologists. The use of seismic arrays is an important tool for detection and analysis of seismic signals typically associated with volcanic activity [Rost and Thomas 2002, 2009]. Necessary conditions for an effective monitoring of the seismic activity in volcanic areas are a good network configuration, a high number of stations, and at least one seismic array. These "hardware" conditions are still insufficient without the continuity of recorded data, their quality, their analysis with appropriate techniques, a correct interpretation of the results, and a knowledge of the monitoring system limits.

At present a real time seismic network of more than 30 stations provides data for an efficient surveillance of the two volcanoes [Orazi et al. 2013]. The increasing request for more data of high quality (digital data, three components, broad band, arrays) lead to the deployment during the past years of many stand-alone seismic stations to improve the monitoring capability for scientific purposes (Figures 1 and 2). Later the switch from analogical to digital data transmission filled the gap of data quality between real time and stand-alone stations. However, stand-alone instruments still have 


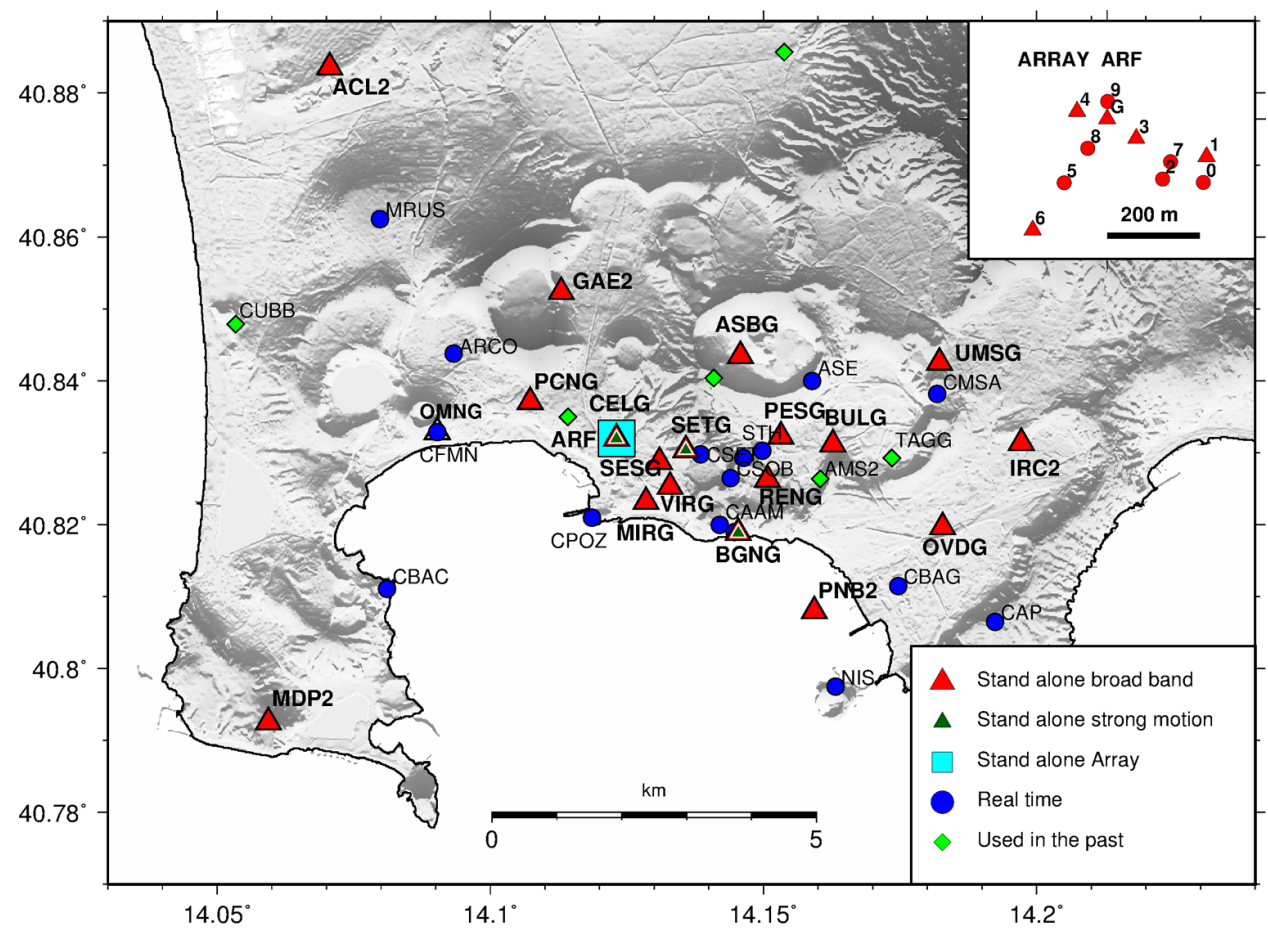

Figure 1. Topography map of Campi Flegrei caldera with the local seismic network currently installed (August 2015). The top right inset shows the current configuration of ARF array.

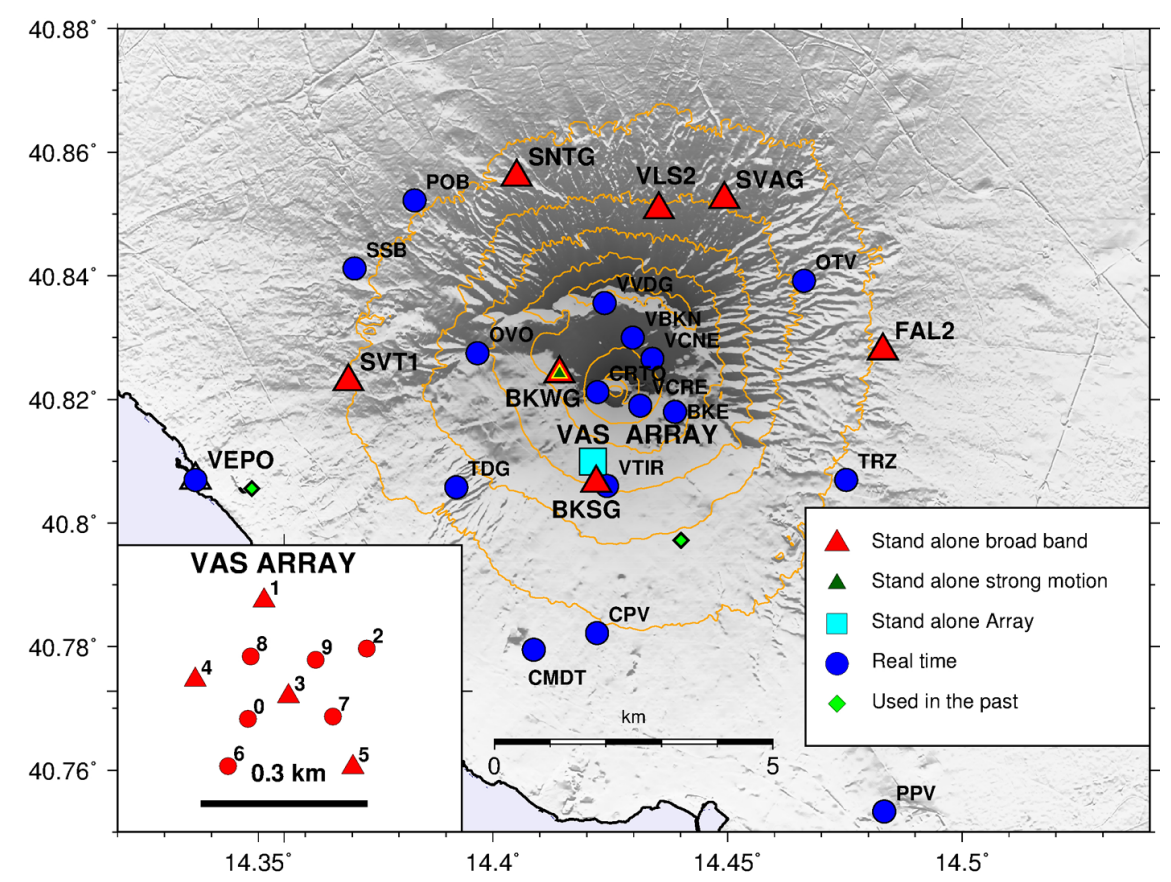

Figure 2. Topography map of Mt. Vesuvius with the local seismic network currently installed (August 2015). The left bottom inset shows the current configuration of VAS array.

some advantage when real time data are not necessary. In fact they may be installed in the most remote sites without any restrictions imposed by the data transmission, and the lower power consumption compared with real time instruments reduces the energy failures in winter time at those stations powered by solar panels. Since stand-alone instruments do not suffer of any possible problems related with the data transmission (and data reception), they ensure high continuity of the data stream, which is a necessary condition for an effective monitoring. During the last five years we collected at least $99.9 \%$ of data (that means continuity without any gaps for months or even years) at many stations, and more than $99 \%$ of data at about half of our stand-alone stations. Data gaps of few minutes may occur in case of ordinary maintenance, while gaps from days to weeks, due to instrument failure, are very rare.

In this paper we describe the stand-alone seismic 

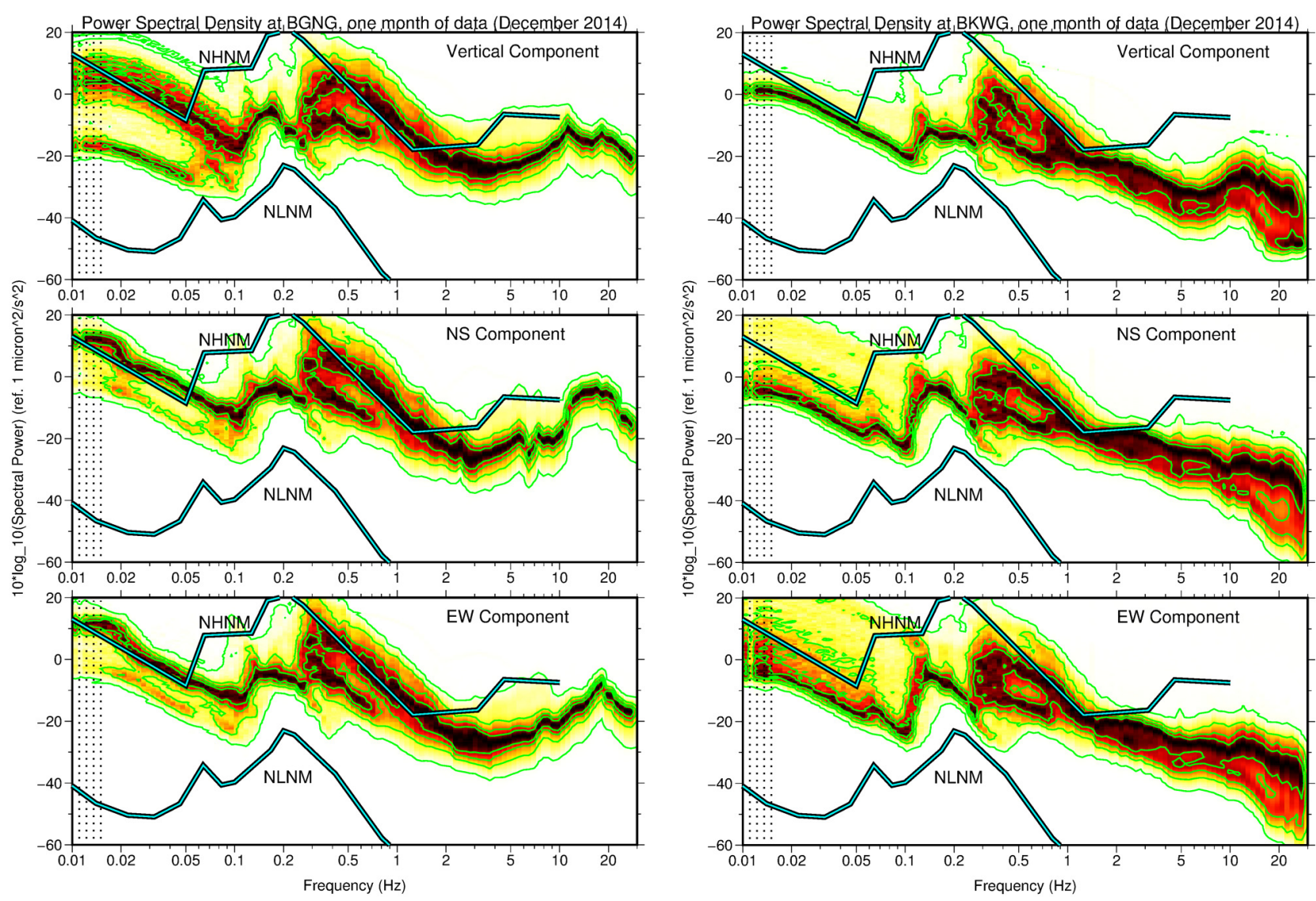

Figure 3. Example of PSD computed over one month of data at two stations, one in Campi Flegrei (BGNG, left) and one at Vesuvius (BKWG, right). For each station the three component PSD are shown and compared with the NLNM and NHNM.

stations and arrays currently installed at Campi Flegrei and Mt. Vesuvius. We provide a quantitative estimation of the background noise, a discussion of the limits of the current monitoring system, and finally we describe some interesting results. Regarding the nomenclature of volcanic earthquakes we consider LF events those characterized by peak frequency in the range $1-5 \mathrm{~Hz}$ and LP events those with the main frequency in the range $0.1-1 \mathrm{~Hz}$.

\section{Features of the background seismic noise}

An efficient monitoring of the seismic activity requires continuous data of high quality from many stations. While the number of stations can be easily increased, the data quality is limited by the high background seismic noise that characterizes both Campi Flegrei and Vesuvius volcanic areas. For this reason the detection threshold of seismic events is higher than usually observed in other volcanic environments, particularly in Campi Flegrei [Del Pezzo et al. 2013]. The detection of low amplitude and emergent signals is particularly affected by the background noise, therefore a quantification of the background signal power is important. To characterize the background noise at any sites we have computed the power spectral density (PSD) over one month of data at any stand-alone sta- tions. Figure 3 shows a few examples of PSD, and compares them with the "new low- and high-noise models" (NLNM and NHNM) [Peterson 1993]. For a comparison of the noise amplitude at all sites among them and with the NLNM and NHNM we show in Figure 4 the spectral power estimated at all stations by averaging over one month of data. The PSD (Figure 3) and average spectral power (Figure 4) show that the background signal is very high at many stations, particularly in the Campi Flegrei area. In the frequency range $0.05-0.4 \mathrm{~Hz}$, 20 out of 22 stations have an average noise smaller than the NHNM, while between $0.5 \mathrm{~Hz}$ and $5 \mathrm{~Hz}$ many stations, the most of which in Campi Flegrei, show a noise power greater than the NHNM. On average the noise power at Vesuvius is lower than Campi Flegrei for frequency higher than $0.2 \mathrm{~Hz}$ (Figure 4). The background signal has various origin in different frequency bands. Signals related with human activity are particularly evident at high frequency $(>5 \mathrm{~Hz}$, likely produced by vehicles, engines, factories), while microseismic noise of marine origin dominates in the $0.1-1 \mathrm{~Hz}$ frequency band. Weather related noise is observed in a broad frequency band $(0.1-10 \mathrm{~Hz})$. Some stations in Campi Flegrei are affected by high level disturbances even at very low frequency, in the $0.01-0.1 \mathrm{~Hz}$ band, mostly produced by the passage of local trains nearby. One of 


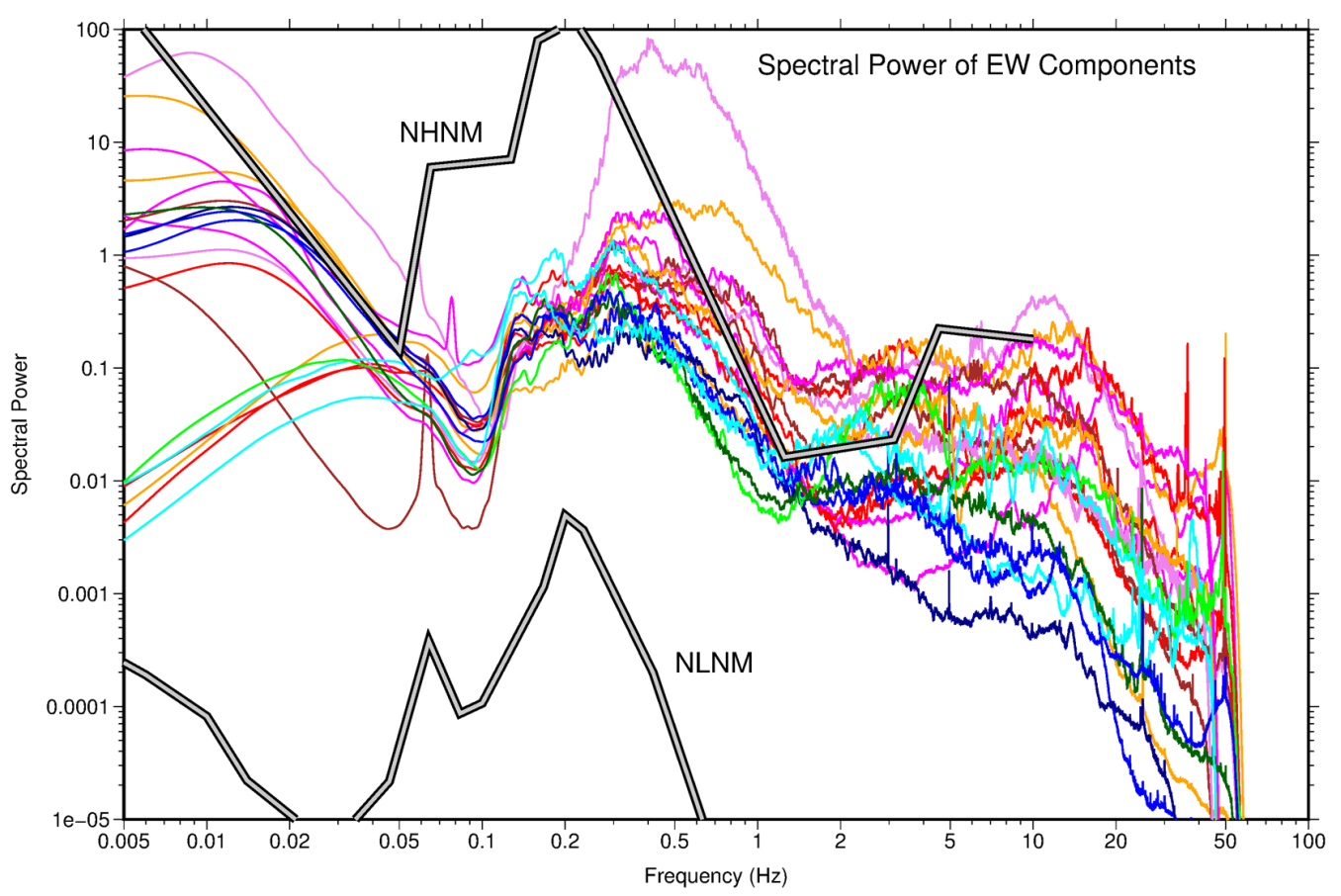

Figure 4. Mean spectral power computed over one month of data at all stand-alone stations currently installed at Campi Flegrei (hot colors) and Vesuvius (cold colors). The results of the EW components are shown and compared with the NLNM and NHNM.

such cases is the station BGNG, whose PSDs are characterized by two branches at frequency smaller than 0.1 $\mathrm{Hz}$ (Figure 3). The lower value branch corresponds to signals recorded during night hours, while the higher level branch is representative of day hour signals, which are greatly affected by a local train running a few tens of meters from the station. A direct consequence of the anthropic noise is the high variability of background signal amplitude between day and night hours. This is particularly evident at frequency greater than about 5 $\mathrm{Hz}$, where daily and weekly cycles are recognized in the amplitude of background signal at all stations. An ex- ample of such analysis in time domain is shown in Figure 5 of La Rocca and Galluzzo [2012]. In some cases we have recognized disturbances of instrumental origin in the recorded data. The most common are calibration pulse-like signals that occur without a well known reason on many broad band seismometers [Zahradnik and Plesinger 2005, 2010]. Some resonances at very low frequency have also been observed, like a monochromatic signal at about $0.06 \mathrm{~Hz}$ at CELG and $0.07 \mathrm{~Hz}$ at UMSG (Geotech KS2000 seismometer).

Beside the local sources of seismic noise, the signal quality depends significantly by site effects, that usually

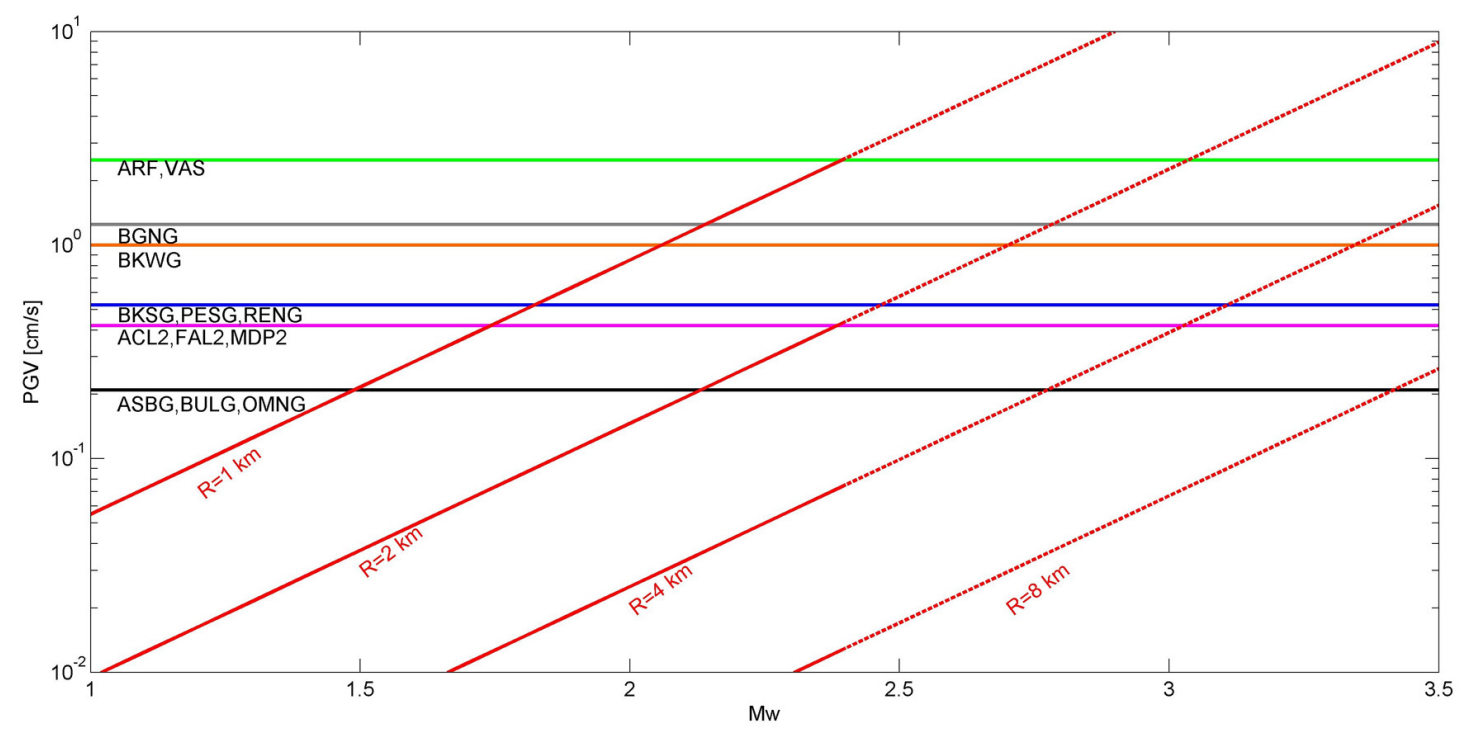

Figure 5. Maximum detectable amplitude of some stand-alone seismic stations currently installed in Campi Flegrei and Vesuvius (horizontal lines), and the theoretical amplitude versus magnitude computed for different hypocentral distances at Campi Flegrei (red lines). The continuous part of red lines identify the magnitude ranges for which GMPEs can be considered reliable $\left(\mathrm{M}_{\mathrm{w}} \in[0.8,2.4]\right.$ for Campi Flegrei). 
are not negligible in volcanic areas [Galluzzo et al. 2009, Tramelli et al. 2010]. In fact volcanoes are always environments characterized by high heterogeneity in the shallowest part due to the presence of loose material alternated with more compact layers like tuff and lava.

\section{Limits of the current monitoring system}

The detection threshold of seismic events in volcanic areas is a complex matter, depending on many factors such as the stations density and the background noise amplitude and spectrum. We have seen that at most of our stations the background signal power in the frequency range $[0.5-5 \mathrm{~Hz}]$ is higher than the NHNM (Figure 4). Volcanic signals typically have the most of energy just in this frequency band. In Campi Flegrei the detection capability of small signals is worsened by the fact that a large part of the caldera is located below the sea, where seismic instruments are not yet installed. Another limit of the monitoring system, often neglected, is the maximum amplitude recordable signal. In fact the investigation of seismic source requires proper recording of the radiated waveform as near the source as possible. This aspect is often critical on volcanoes, where the seismic source may be rather complex and recorded signals are usually strongly affected by path effects. Therefore recording seismic signals without saturation at the stations near the epicenter is crucial for source study. Modern instruments have evolved toward a continuous broadening of the frequency range of detectable signals. Thus, in a few years a high number of broad band and very broad band seismometers have been installed on volcanoes with the aim of detecting LP, VLP, ULP signals likely produced by the magma movement beneath the volcano. Since this kind of volcanic signals usually have low amplitude, the instrument producers have gradually increased the sensitivity and the dynamic range. Modern broad band seismometers have gain in the range from $800 \mathrm{~V} / \mathrm{m} / \mathrm{s}$ (Guralp) to $2000 \mathrm{~V} / \mathrm{m} / \mathrm{s}(\mathrm{Gu}-$ ralp, Geotech), and dynamic range of about $140 \mathrm{~dB}$. They are characterized by very high sensitivity, being able to reproduce ground movements as small as few $\mathrm{nm} / \mathrm{s}$. Unfortunately such high sensitivity is useless in places like Campi Flegrei and Mt. Vesuvius, where the background noise is very high. On the other hand, the dynamic range of modern broad band seismometers limits the maximum reproducible ground shaking to few $\mathrm{mm} / \mathrm{s}$. Another limit on the maximum amplitude recordable signal is given by the input range of the acquisition system. A modern data logger characterized by (nominal) dynamic range of $144 \mathrm{~dB}$ (corresponding to 24 bit ADC), coupled with a broad band seismometer with gain of $2000 \mathrm{~V} / \mathrm{m} / \mathrm{s}$ will resolve very well the weakest ground motion, but will saturate the recorded signal for ground velocity of few $\mathrm{mm} / \mathrm{s}$. Therefore, even moderate magnitude local earthquakes may produce clipped waveforms. Figure 5 shows the maximum signal amplitude we expect to be recorded by the standalone seismic stations installed in Campi Flegrei and Vesuvius. Values are different because they depend on the sensor gain and the input range of the acquisition system. In our case the worst combination is given by the Marslite data logger $( \pm 4.2 \mathrm{~V}$ input range, $120 \mathrm{~dB}$ dynamic range) coupled with the Geotech KS2000 and Guralp CMG-40T seismometers $(2000 \mathrm{~V} / \mathrm{m} / \mathrm{s})$, while the best performance is expected from the arrays, composed of Reftek data logger ( $\pm 10 \mathrm{~V}$ input range, $144 \mathrm{~dB}$ dynamic range) and Lennartz LE3Dlite short period seismometers $(400 \mathrm{~V} / \mathrm{m} / \mathrm{s}, 120 \mathrm{~dB}$ dynamic range). However, in this last case the dynamic range of the data logger is greater than the dynamic range of the seismometer, thus the strongest recorded signals probably do not reproduce correctly the ground motion (for more technical details see for example Havskov and Alguacil [2004]). In the past years we have seen seismic signals clipping the recorded broad band data for regional earthquakes and even for major teleseisms. As an example, the M6.3 L'Aquila earthquake of April 6, 2009, located $185 \mathrm{~km}$ from Campi Flegrei, saturated all recordings of our broad band stations.

The ground motion prediction equation (GMPE) evaluated for Campi Flegrei [Galluzzo et al. 2015] was used to compute the PGV (peak ground velocity) for various magnitudes and hypocentral distances, as shown in Figure 5. This computation holds strictly up to Mw2.4, the maximum detected earthquake, while values for higher magnitude have been extrapolated. The result indicates that a shallow earthquake $(2 \mathrm{~km}$ of hypocentral distance) of magnitude 3 would saturate the recorded data at most of broad band stations near the epicenter. Unfortunately no earthquakes stronger than Mw2.4 occurred at Campi Flegrei since broad band stations have been using, therefore we do not have experimental data to compare with our theoretical curves. Since the source study is greatly improved by near source recordings, the use of accelerometers is very important for this purpose because they are characterized by a much higher clipping level with respect to any seismometer.

\section{Data and methods}

Figures 1 and 2 show the stand-alone seismic stations operating in Campi Flegrei and Mt. Vesuvius, respectively. Actually (August 2015) 18 stations and one array are deployed in Campi Flegrei (Table 1), while seven stations and one array are operative at Mt. Vesuvius (Table 2). 


\begin{tabular}{|c|c|c|c|c|c|c|c|c|}
\hline $\begin{array}{l}\text { Station } \\
\text { name }\end{array}$ & $\begin{array}{l}\text { Data } \\
\text { logger }\end{array}$ & Sensor & $\begin{array}{l}\text { Sensor } \\
\text { period }\end{array}$ & $\begin{array}{c}\text { Installation } \\
\text { date }\end{array}$ & $\begin{array}{l}\text { Samp. } \\
\text { freq. }\end{array}$ & Lat. & Lon. & $\begin{array}{l}\text { Elev. } \\
(\mathrm{m})\end{array}$ \\
\hline ACL2 & Marslite & Lennartz LE3D & $20 \mathrm{~s}$ & January 2011 & 125 & 40.8836 & 14.0706 & 55 \\
\hline ASBG & Marslite & Guralp CMG-40T & $60 \mathrm{~s}$ & November 2004 & 125 & 40.8435 & 14.1459 & 12 \\
\hline BGNG & Reftek 130 & Guralp CMG-40T & $60 \mathrm{~s}$ & October 2005 & 100 & 40.8189 & 14.1454 & 4 \\
\hline BGNK & & Episensor FBA ES-T & & & 100 & & & \\
\hline BULG & Marslite & Guralp CMG-40T & $60 \mathrm{~s}$ & February 2010 & 125 & 40.8312 & 14.1627 & 18 \\
\hline CELG & Reftek 130 & Geotech KS2000 & $120 \mathrm{~s}$ & March 2008 & 100 & 40.8320 & 14.1231 & 50 \\
\hline CELK & & Episensor FBA ES-T & & & 100 & & & \\
\hline GAE2 & Marslite & Lennartz LE3D & $20 \mathrm{~s}$ & January 2013 & 125 & 40.85237 & 14.11298 & 100 \\
\hline IRC2 & K2 & Lennartz LE3D & $20 \mathrm{~s}$ & November 2011 & 100 & 40.8314 & 14.1972 & 40 \\
\hline MDP2 & Marslite & Lennartz LE3D & $20 \mathrm{~s}$ & December 2012 & 125 & 40.79257 & 14.05938 & 130 \\
\hline MIRG & Marslite & Guralp CMG-40T & $60 \mathrm{~s}$ & July 2015 & 125 & 40.8232 & 14.1285 & 35 \\
\hline $\mathrm{OMNG}^{\star}$ & Marslite & Guralp CMG-40T & $60 \mathrm{~s}$ & June 2005 & 125 & 40.8333 & 14.0904 & 40 \\
\hline OVDG & M24 & Geotech KS2000 & $120 \mathrm{~s}$ & April 2003 & 100 & 40.8197 & 14.1827 & 14 \\
\hline PCNG & Taurus & Guralp CMG-40T & $60 \mathrm{~s}$ & March 2015 & 100 & 40.8371 & 14.1073 & 50 \\
\hline PESG & Marslite & Guralp CMG-40T & $60 \mathrm{~s}$ & February 2011 & 125 & 40.8323 & 14.1532 & 45 \\
\hline PNB2 & Marslite & Lennartz LE3D & $20 \mathrm{~s}$ & October 2014 & 125 & 40.8080 & 14.1593 & 10 \\
\hline RENG & Marslite & Guralp CMG-40T & $60 \mathrm{~s}$ & January 2011 & 125 & 40.82630 & 14.15072 & 55 \\
\hline SESG & Gilda & Guralp CMG-40T & $60 \mathrm{~s}$ & July 2015 & 100 & 40.82876 & 14.13096 & 75 \\
\hline SETG & Taurus & Geotech KS2000 & $120 \mathrm{~s}$ & May 2011 & 100 & 40.8304 & 14.1358 & 150 \\
\hline SETK & Trident & Episensor FBA ES-T & & & 100 & & & \\
\hline SETT & Trident & Tiltmeter AG 702 & & November 2014 & 10 & & & \\
\hline UMSG & Reftek 130 & Geotech KS2000 & $120 \mathrm{~s}$ & May 2013 & 100 & 40.84256 & 14.18222 & 120 \\
\hline VIRG & Reftek 130 & Guralp CMG-40T & $60 \mathrm{~s}$ & March 2015 & 100 & 40.8253 & 14.1329 & 65 \\
\hline ARF array & Reftek 130-18MC & 10 Lennartz LE3D-lite & $1 \mathrm{~s}$ & August 2010 & 100 & 40.8320 & 14.1231 & 50 \\
\hline
\end{tabular}

Table 1. Campi Flegrei stand-alone seismic network (August 2015). Notes: ( $\left.{ }^{\star}\right)$ OMNG was uninstalled on March 2015 because replaced by a real time station (CFMN).

\begin{tabular}{|c|c|c|c|c|c|c|c|c|}
\hline $\begin{array}{l}\text { Station } \\
\text { name }\end{array}$ & $\begin{array}{l}\text { Data } \\
\text { logger }\end{array}$ & Sensor & $\begin{array}{l}\text { Sensor } \\
\text { period }\end{array}$ & $\begin{array}{c}\text { Installation } \\
\text { date }\end{array}$ & $\begin{array}{l}\text { Samp. } \\
\text { freq. }\end{array}$ & Lat. & Lon. & $\begin{array}{c}\text { Elev. } \\
(\mathbf{m})\end{array}$ \\
\hline BKSG & Marslite & Guralp CMG-40T & $60 \mathrm{~s}$ & October 2008 & 125 & 40.8065 & 14.4220 & 600 \\
\hline BKWG & Taurus & Guralp CMG-40T & $60 \mathrm{~s}$ & October 2008 & 100 & 40.8242 & 14.4143 & 834 \\
\hline BKWK & Trident & Episensor FBA ES-T & & March 2011 & 100 & & & \\
\hline BKWT & Trident & Tiltmeter AG 702 & & & 10 & & & \\
\hline $\mathrm{EPO}^{\star}{ }^{\star}$ & Taurus & Lennartz LE3D & $20 \mathrm{~s}$ & February 2011 & 100 & 40.80698 & 14.33660 & 5 \\
\hline $\mathrm{EPOK}^{\star}$ & Trident & Episensor FBA ES-T & & & 100 & & & \\
\hline FAL2 & Marslite & Lennartz LE3D & $20 \mathrm{~s}$ & March 2013 & 125 & 40.8279 & 14.4831 & 176 \\
\hline SNTG & Marslite & Guralp CMG-40T & $60 \mathrm{~s}$ & April 2014 & 125 & 40.85602 & 14.40507 & 255 \\
\hline SVAG & Marslite & Guralp CMG-40T & $60 \mathrm{~s}$ & May 2012 & 125 & 40.85238 & 14.44933 & 373 \\
\hline SVT1 & K2 & Lennartz LE3D lite & $1 \mathrm{~s}$ & February 2015 & 100 & 40.8229 & 14.3692 & 195 \\
\hline VLS2 & Taurus & Lennartz LE3D & $20 \mathrm{~s}$ & January 2015 & 100 & 40.85072 & 14.43535 & 430 \\
\hline VAS array & Reftek 130-18MC & 10 Lennartz LE3D-lite & $1 \mathrm{~s}$ & March 2012 & 100 & 40.80993 & 14.42130 & 662 \\
\hline
\end{tabular}

Table 2. Vesuvius stand-alone seismic network (August 2015). Notes: $\left(^{\star}\right)$ EPO2 and EPOK were dismissed in January 2015 because replaced by a real time station (VEPO). 
In October 2012 the configuration of ARF array (Campi Flegrei) was increased from the original 6 stations [La Rocca and Galluzzo 2012] to 10 stations to improve the array performance at higher frequency. Each one of the two arrays is composed of 10 short period seismometers connected by cables to a 18 channel data logger (Reftek 130-MC18A). The two arrays were installed with the specific purpose of detecting low amplitude coherent signals possibly related with the volcanic activity, first of all the volcanic tremor. A detailed description of the two arrays, the analysis currently performed and some examples of interesting signals are given by La Rocca and Galluzzo [2012, 2014]. A synthesis of the instrument type for each station is given in Table 1 for Campi Flegrei and in Table 2 for Mt. Vesuvius. Data recorded by stand-alone stations and arrays are periodically collected and archived in hour-long files in SAC format [Goldstein et al. 2003, Goldstein and Snoke 2005].

We start our search for seismic signals possibly related with volcanic activity by the analysis of all data collected by the two arrays. We apply the beam-forming (BF) and high-resolution (HR) methods [Capon 1969] focusing the analysis at the following frequencies: $1 \mathrm{~Hz}$, $1.5 \mathrm{~Hz}, 2 \mathrm{~Hz}, 3 \mathrm{~Hz}, 4 \mathrm{~Hz}, 5 \mathrm{~Hz}$. We also apply the Semblance method [Neidell and Taner 1971] in time domain to seismograms bandpass filtered in the following frequency bands: $0.5-2 \mathrm{~Hz}, 1-2 \mathrm{~Hz}, 1-3 \mathrm{~Hz}, 2-4 \mathrm{~Hz}, 3-$ $5 \mathrm{~Hz}$. Results of such analyses are plotted in day-long pictures for each method and any frequency, showing signal amplitude (mean among the array stations), coherence or semblance, backazimuth and slowness. Results of time windows that have coherence (semblance) greater than an arbitrary chosen threshold are plotted by bigger bold symbol to make them more visible in the background distribution of values. Figure 6 shows as an example the results of $\mathrm{BF}$ and $\mathrm{HR}$ analysis at frequency of $1.5 \mathrm{~Hz}$ for one day of data at ARF array. Looking at the coherence of the seismic wavefield we can identify transient signals different from seismic noise and potentially interesting for monitoring purposes. Usually this selection procedure yields tens of events per week, the most of which are artificial events, while some are local and regional earthquakes. Those not recognized as earthquakes are further investigated by looking at the data recorded by the stand-alone stations. The seismic signals with the features compatible with local natural sources (volcanic tremor, LF and LP earthquakes) that are visible at many stations are then analyzed by using all available data.

Automatic picking algorithms are not efficient in the search of events characterized by emergent onset and low signal to noise ratio like LF, LP earthquakes and tremor. Therefore, beside the analysis of array data, we search for volcanic events in the signals of the stand-alone network by looking at the amplitude of continuous data. We compute the rms over a sliding window by taking the mean among the three compo-

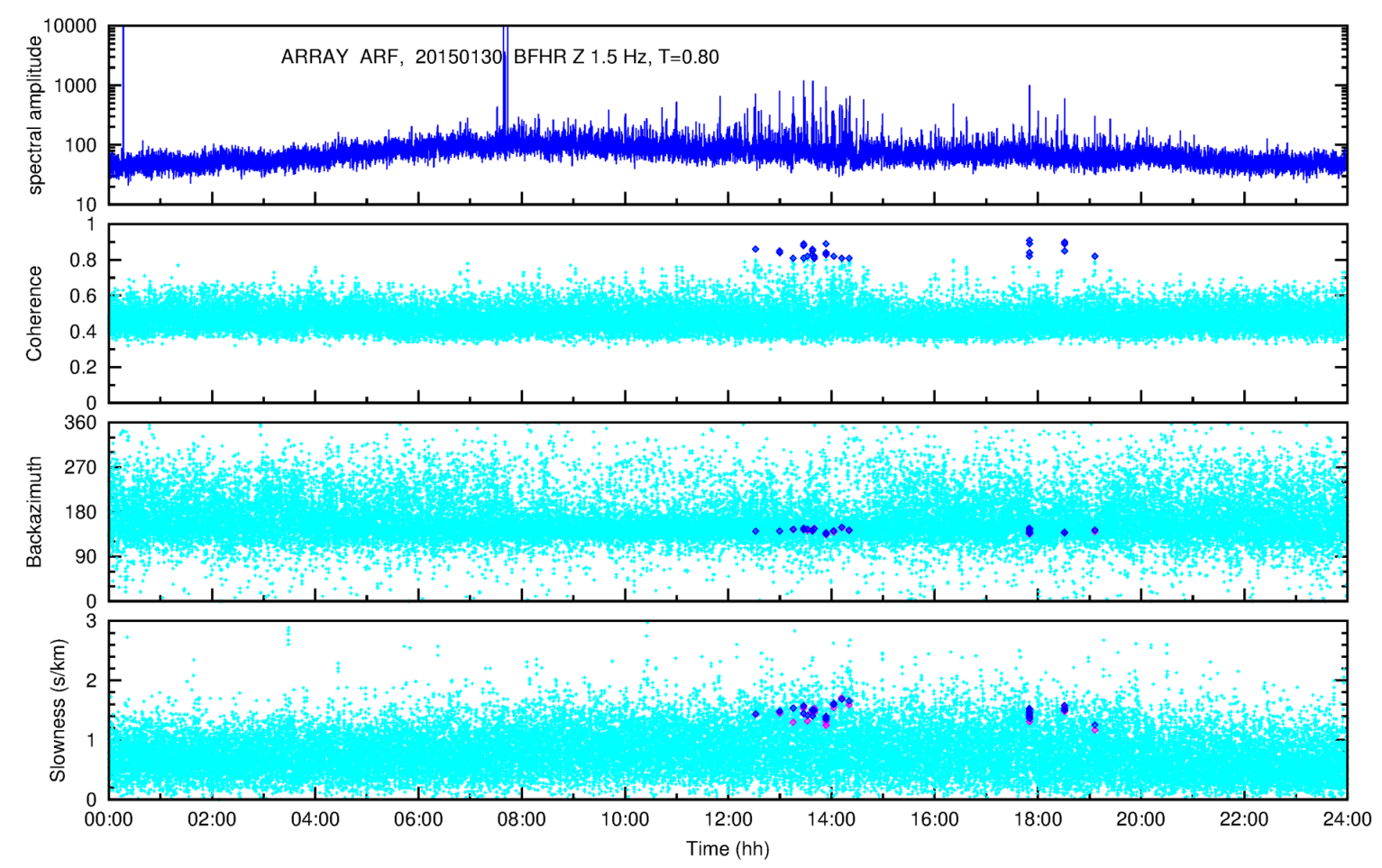

Figure 6. Example of day long results of BF and HR analysis at ARF array for the day January 30, 2015. Top plot shows the average spectral amplitude, then coherence, backazimuth and slowness are shown in the following plots. Results of the windows with coherence greater than 0.8 are shown by blue (BF) and magenta (HR) symbol to make them more visible among the background results. 


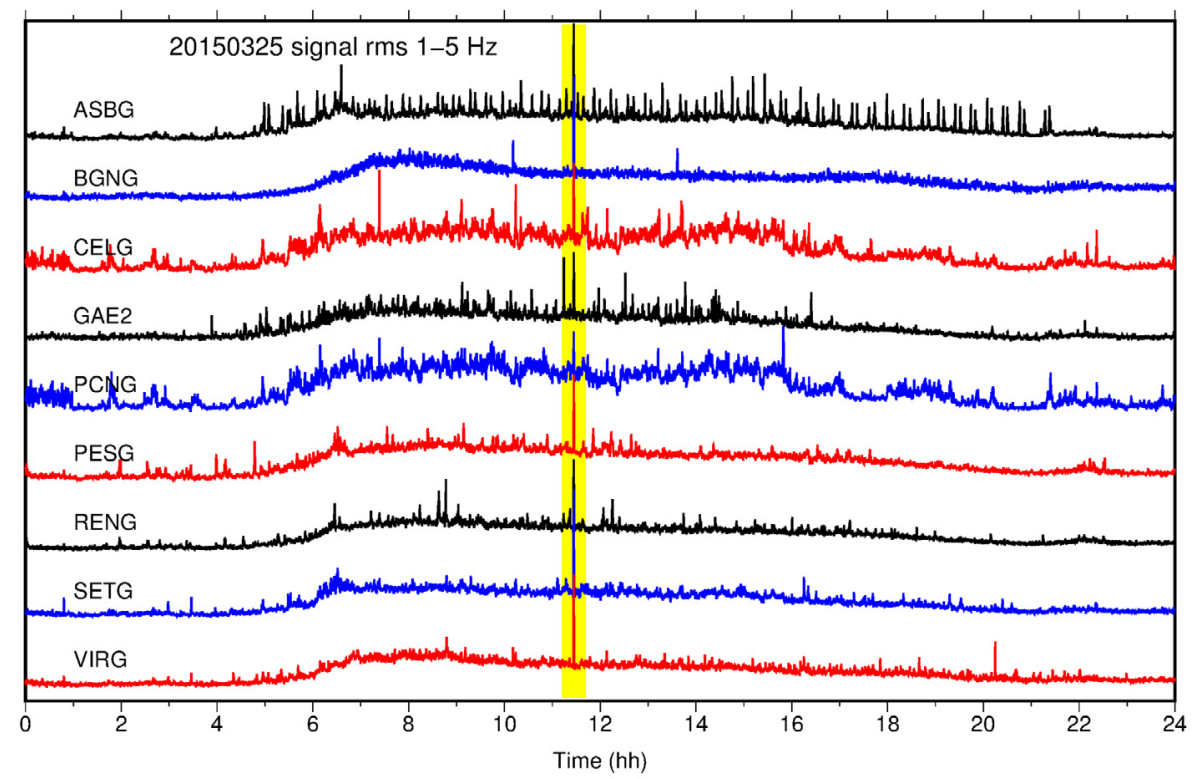

Figure 7. Average rms (among the three components) of the seismic signals recorded by many stand-alone stations in the Campi Flegrei area on March 25, 2015. Signals were bandpass filtered between $1 \mathrm{~Hz}$ and $5 \mathrm{~Hz}$, and the rms was computed over $10 \mathrm{~s}$ sliding window. The yellow background color marks an amplitude peak common to all stations, representative of a LF earthquake.

nents. Signals are bandpass filtered in several frequency bands to make the analysis more selective. The most important bands of analysis are $1-5 \mathrm{~Hz}$ for volcanic tremor and LF earthquakes, and $0.2-1 \mathrm{~Hz}$ for LP earthquakes. Amplitude peaks common to many stations reveal the presence of seismic events. Although the most of them are local and regional earthquakes, many LF earthquakes of volcanic origin have been identified through this analysis. On the contrary, we have not detected any signals classified as LP earthquake (peak frequency between $0.1 \mathrm{~Hz}$ and $1 \mathrm{~Hz}$ ). An example of day long rms at many stations of Campi Flegrei area is shown in Figure 7. This analysis is performed by considering the stand-alone stations characterized by the lowest background noise. In Campi Flegrei area the best stations are ASBG, BGNG, CELG, OMNG, SETG, RENG, PESG, VIRG, while at Vesuvius the best ones are BKSG, BKWG, SNTG and SVAG.

\section{Results for Campi Flegrei}

During the last decade the seismic activity at Campi Flegrei has been very low, characterized by low magnitude VT earthquakes $(\mathrm{M}<2.0)$, often occurring as swarms. A large swarm of LP earthquakes consisting of more than 800 events occurred in October 2006 [Saccorotti et al. 2007]. From its installation (August 2010) to date (August 7, 2015) ARF array has recorded 1808 days of data with a great continuity. Only one gap of few hours caused by a power failure occurred during the last three years. The analysis of ARF array data recorded during the last five years has shown the occurrence of few LF earthquakes and several tremor-like events. Most of such signals have low SNR and emer- gent onset, therefore their study is difficult and their classification may remain uncertain. Here we describe the unique event classified as volcanic tremor ever recorded in Campi Flegrei by modern instruments, occurred on January 30, 2015. The results of array analysis at frequency $1.5 \mathrm{~Hz}$ (Figure 6) and $2 \mathrm{~Hz}$ of the data recorded on January 30 show the presence of coherent bursts of energy for many hours during the day, particularly from 12:00 to 15:00. These coherent signals have low signal to noise ratio, but all of them are characterized by the same backazimuth from SE (between 135 and 150 degrees) and similar apparent velocity of about $0.7 \mathrm{~km} / \mathrm{s}$ (Figure 6). The bursts of energy coherent at the array ARF are easily recognized in the signals recorded by many stations in the central part of the caldera (Figure 8). The highest SNR is observed in the frequency band between $1.2 \mathrm{~Hz}$ and $2.6 \mathrm{~Hz}$. A careful inspection of the three component filtered seismograms excludes fault dislocation among the possible source mechanisms because no impulsive $P$ or $S$ waves are recognized at any stations. On the contrary, both spectral contents and waveform features suggest that each burst of coherent energy is a small shallow LF earthquake. However, counting individual events is not possible because often they are too close in time to each other and they have different amplitude among them, thus the resulting signal looks likely produced by a nearly continuous source. This hypothesis is supported by the distribution of backazimuth values, where the directions between 130 and 160 degrees (the same of the strongest burst of energy) are the most common even for the less coherent background signal (Figure 6). The most likely source of such signals is a sequence of 


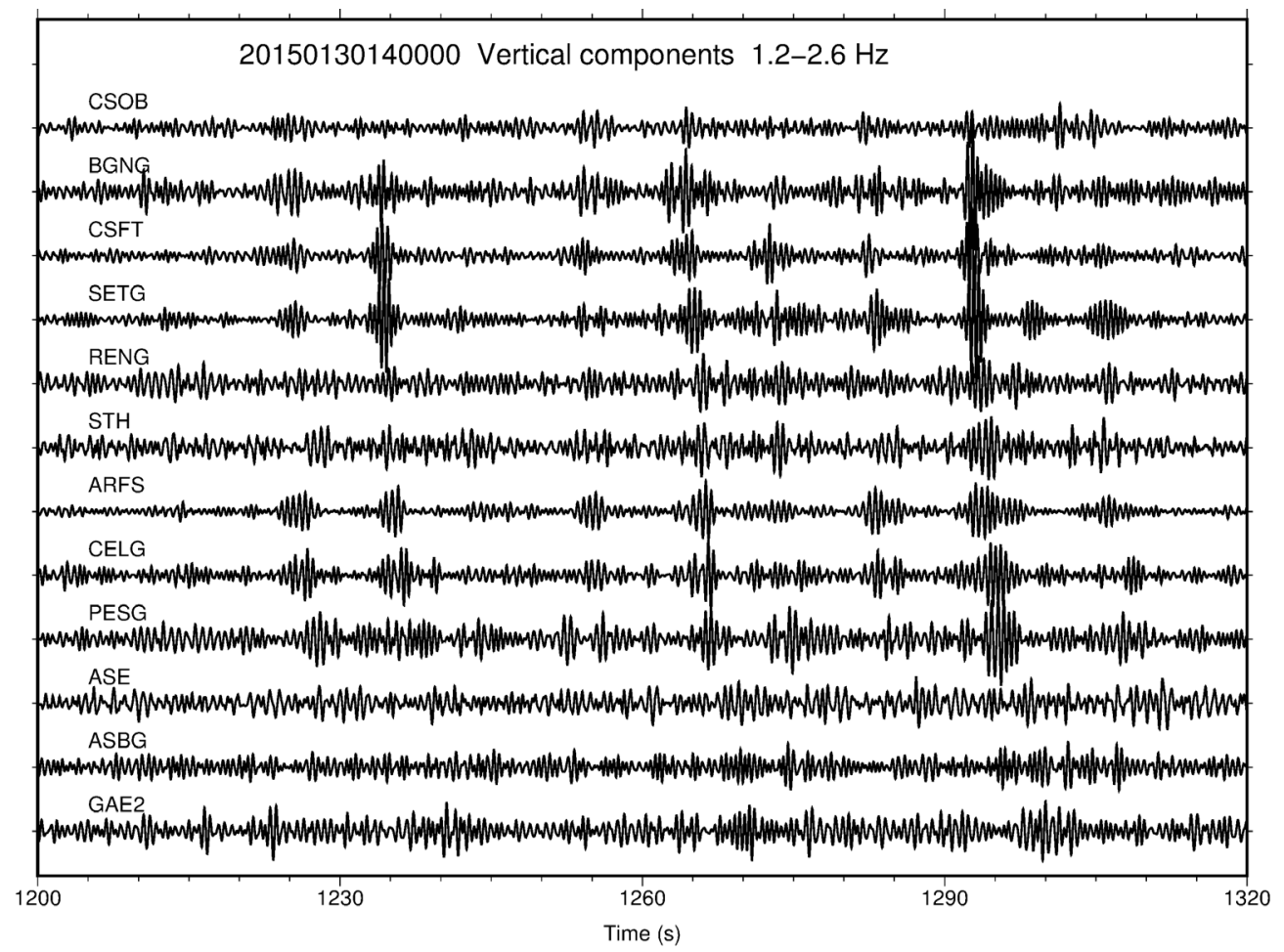

Figure 8. Vertical component seismograms of many seismic stations in the central area of Campi Flegrei caldera showing the tremor signals recorded on January 30, 2015. Signals have been bandpass filtered between $1.2 \mathrm{~Hz}$ and $2.6 \mathrm{~Hz}$ to improve the signal to noise ratio. ARFS is the signal obtained by stacking ARF array data.

LF earthquakes of hydrothermal origin. Seismic events tightly related with the hydrothermal activity have been observed in the past in Campi Flegrei area. The most important case was the swarm of LP earthquakes occurred in October 2006 [Saccorotti et al. 2007, Cusano et al. 2008]. Those events were located at shallow depth (between $0.5 \mathrm{~km}$ and $1 \mathrm{~km}$ ) below the Solfatara crater, were stronger than those observed recently at ARF array and had a predominant frequency of $0.8-1.0 \mathrm{~Hz}$. The low apparent velocity of the coherent signals recorded on January 30, 2015, suggests the predominance of surface waves in the wavefield. On the other hand $\mathrm{P}$ and $\mathrm{S}$ waves are not seen in the waveform at any stations where the signal is recognizable. The absence of impulsive phases prevent a precise location with methods based on the inversion of picked onset time. However, a careful observation of the strongest signals at the stations of the local network permits a raw location of the epicentral area in the circle drawn in Figure 9. The uncertainty on this location is large because some stations were not available, thus the station gap is at least 180 degrees. Regarding the source depth, the low apparent velocity indicates that it must be quite shallow, probably no more than $0.5 \mathrm{~km}$.

The observation of amplitude peaks common to many stations allowed for the discovery of some LF earthquakes. One notable example is shown in Figure 7, where a high peak at 11:25 simultaneous at all stations, highlighted by the yellow background, represents a LF earthquake. The seismograms of this event are shown in Figure 10, bandpass filtered between $1 \mathrm{~Hz}$ and $4 \mathrm{~Hz}$. The signal is characterized by low amplitude, low frequency (the most of energy in the $1-4 \mathrm{~Hz}$ band), and emergent onset at all stations. Since impulsive phases are not seen at any stations, the source location is very uncertain but compatible with the same epicentral area of the tremor observed on January 30 (Figure 9), while the depth must be quite shallow, probably less than 0.5 $\mathrm{km}$, as inferred from the large amount of surface waves that give the main contribution to the wavefield. This LF earthquake is strong enough to be recorded in an area of at least $6 \mathrm{~km}$ of radius in spite of the high background noise that characterizes the central hours of the day.

\section{Results for Mt. Vesuvius}

The seismicity of Mt. Vesuvius during the last decade consists of hundreds of low magnitude volcanotectonic earthquakes every year [D'Auria et al. 2013]. LF earthquakes are very rare, with a few small events [Cusano et al. 2013], while volcanic tremor had never been observed by modern instruments until the installation of VAS array. From March 2012 to date (August 6, 2015), VAS array has recorded 1198 days of data. During the last two years the acquisition was continuous without any gaps. Taking advantage of these array data and the more than 20 stations currently installed, we were able to identify some LF events and a few signals that have all features of volcanic tremor. Here we 


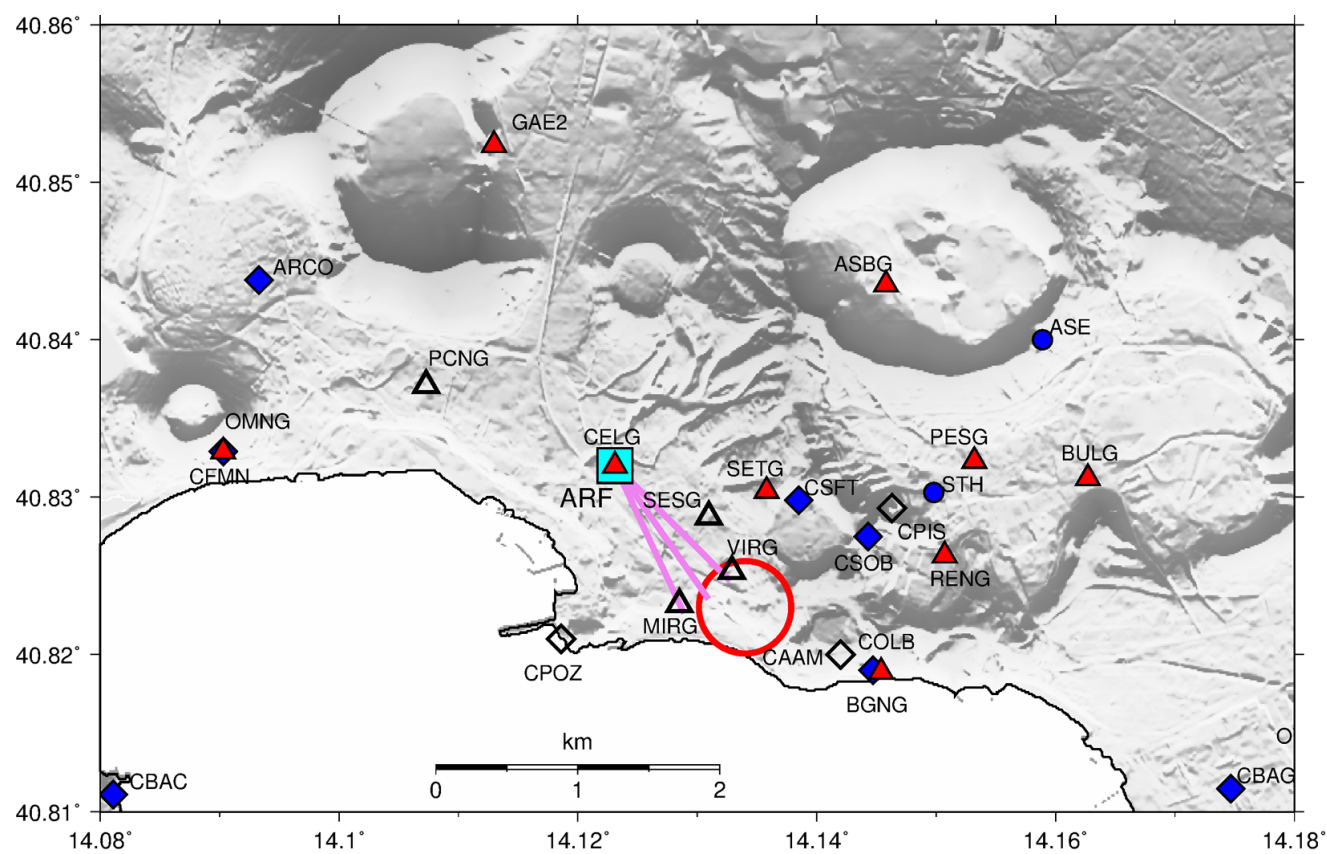

Figure 9. Raw epicentral area (circle) of the hydrothermal volcanic tremor recorded in Campi Flegrei on January 30, 2015. The backazimuth range obtained by array analysis of ARF data is shown by magenta lines, while empty symbols represent seismic stations not available on that day (VIRG, MIRG, SESG and PCNG were installed later).

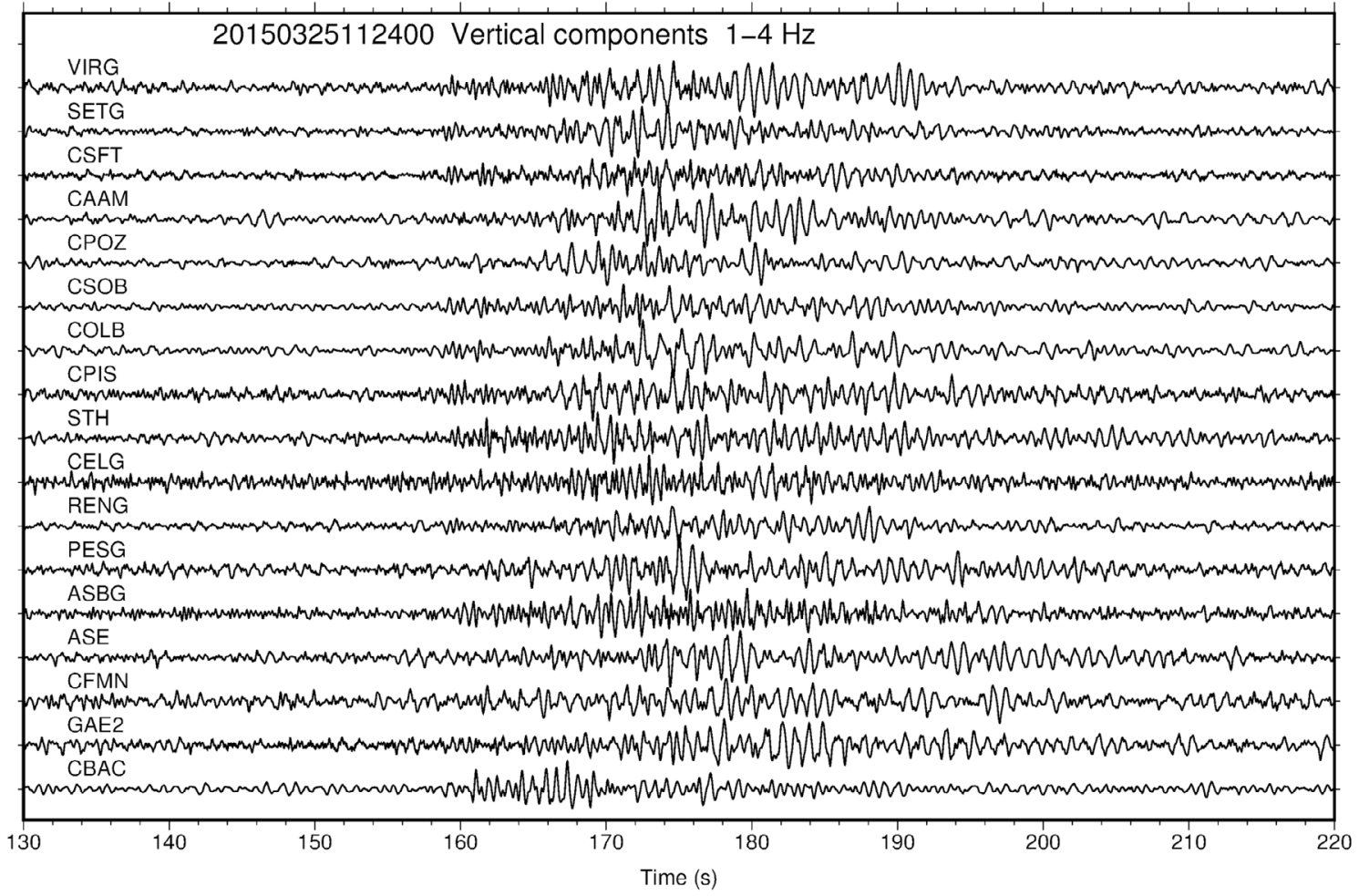

Figure 10. Low Frequency earthquake recorded in Campi Flegrei caldera on March 25, 2015. Signals are bandpass filtered between $1 \mathrm{~Hz}$ and $4 \mathrm{~Hz}$ and roughly ordered with epicentral distance increasing from top to bottom.

describe one LF earthquake and one short burst of volcanic tremor

Figure 11 shows a low-frequency earthquake recorded by many stations of Vesuvius network on December 8, 2014. Seismograms have been bandpass filtered between $1 \mathrm{~Hz}$ and $4 \mathrm{~Hz}$, the frequency band where the most of energy is observed. Although the typical emergent onset prevents a precise location of the source, the high number of stations well distributed around the epicenter partly compensates for the emergent onset, allowing to establish that the source is located below the crater. Careful inspection of the seis- 


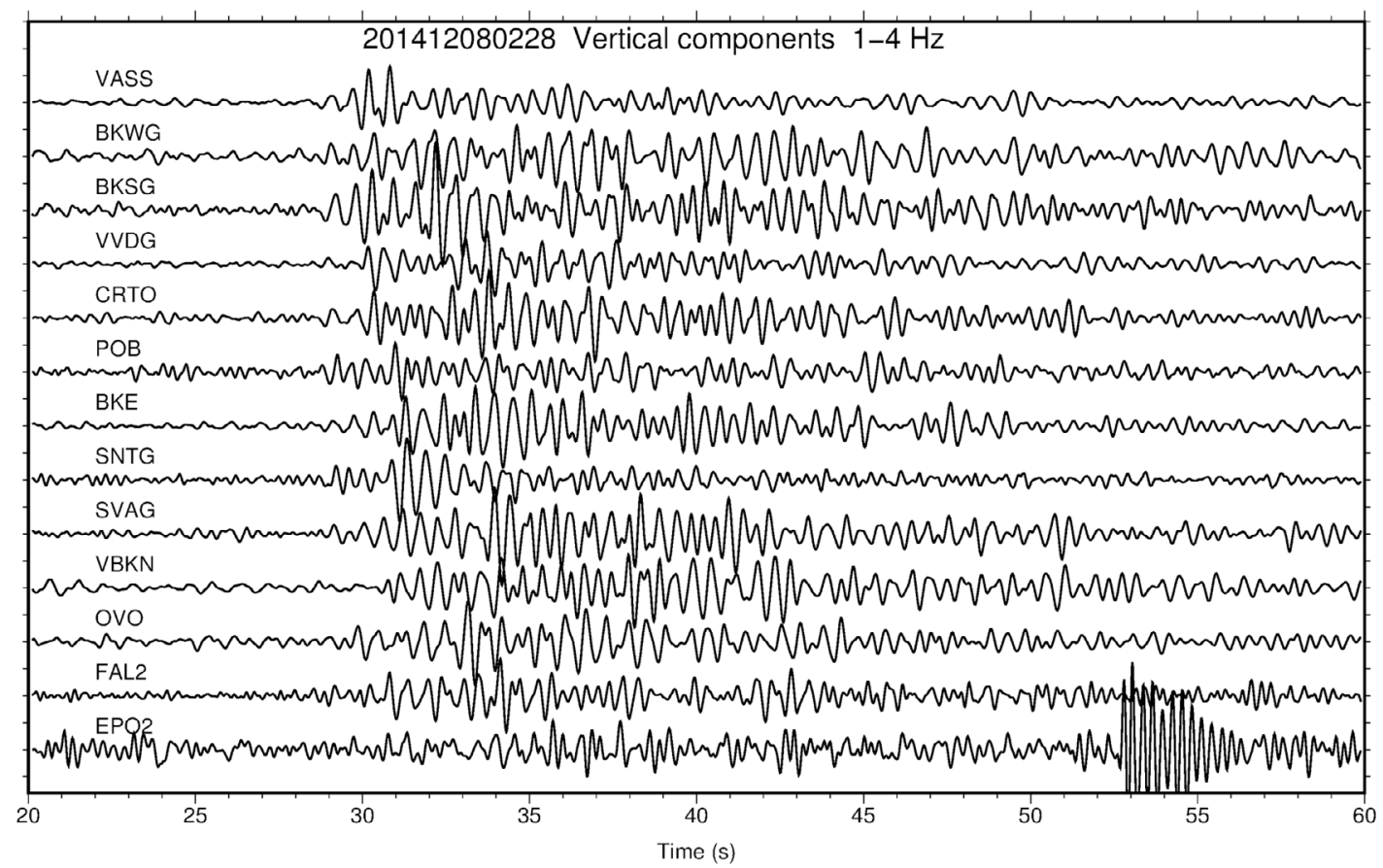

Figure 11. Low Frequency earthquake recorded at Mt. Vesuvius on December 8, 2014. The figure shows the vertical component seismograms of many stations, bandpass filtered between $1 \mathrm{~Hz}$ and $4 \mathrm{~Hz}$ to improve the signal to noise ratio.

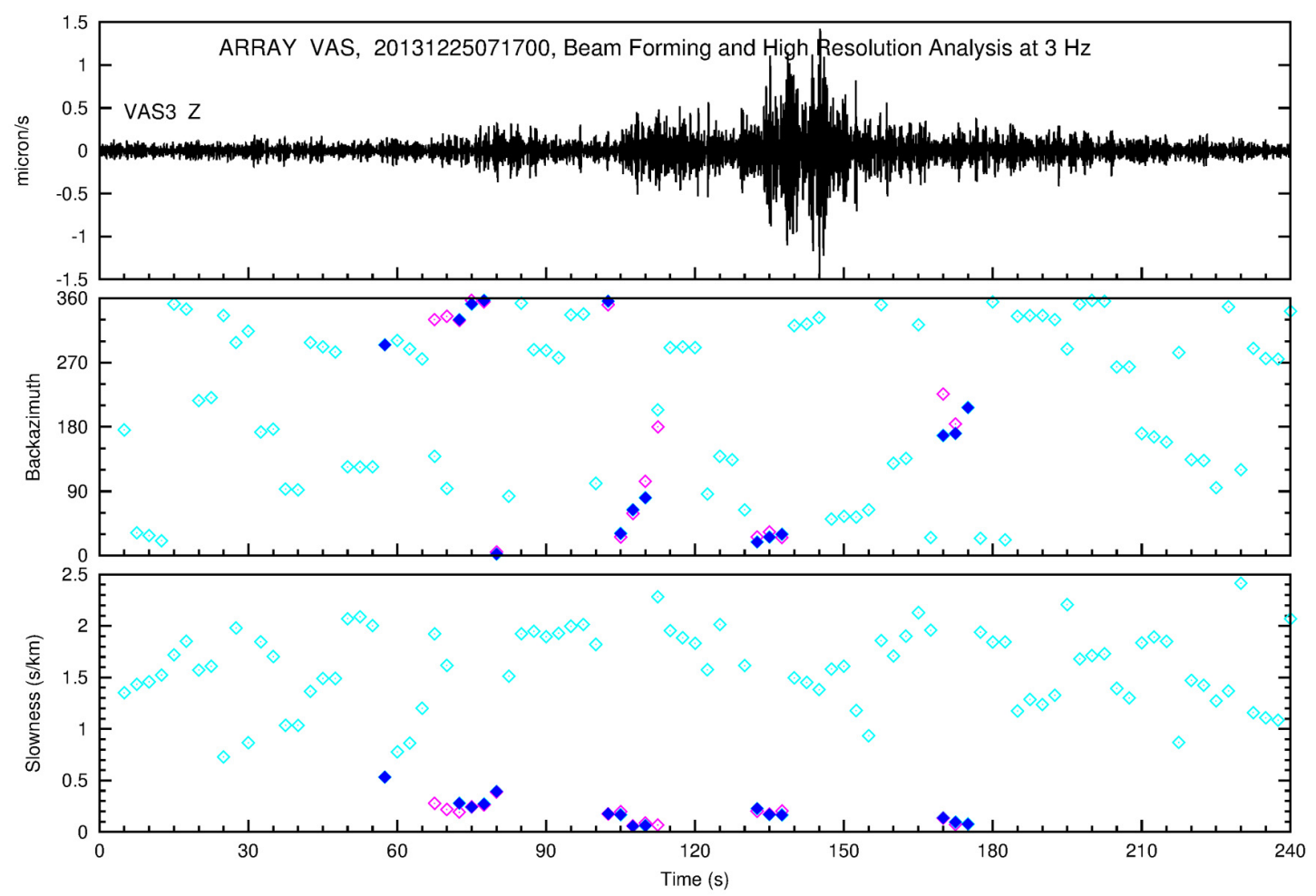

Figure 12. A short burst of volcanic tremor recorded by VAS array on December 25, 2013. The figure shows one vertical component seismogram (VAS3) bandpass filtered between $2 \mathrm{~Hz}$ and $4 \mathrm{~Hz}$, backazimuth and slowness estimated by the array analysis focused at frequency of $3 \mathrm{~Hz}$. Results of time windows with slowness smaller than $0.5 \mathrm{~s} / \mathrm{km}$ are plotted by bold symbols for beam-forming (blue) and high-resolution (magenta) to make more evident the body waves contribution to the recorded signals.

mograms permitted to identify $\mathrm{P}$ and $\mathrm{S}$ waves with an uncertainty of about $0.1-0.2 \mathrm{~s}$ at a few stations, such as BKWG and VASS (stacking of VAS array signals). The estimated Ts-Tp between $1.2 \mathrm{~s}$ and $1.5 \mathrm{~s}$ at these stations (very near the epicenter) is a strong constrain on the source depth, which is estimated to be in the range $4.5-6.5 \mathrm{~km}$ bsl.

An example of volcanic tremor, identified through the analysis of VAS array data, is shown in Figures 12 and 13. Figure 12 displays one seismogram (VAS3, 


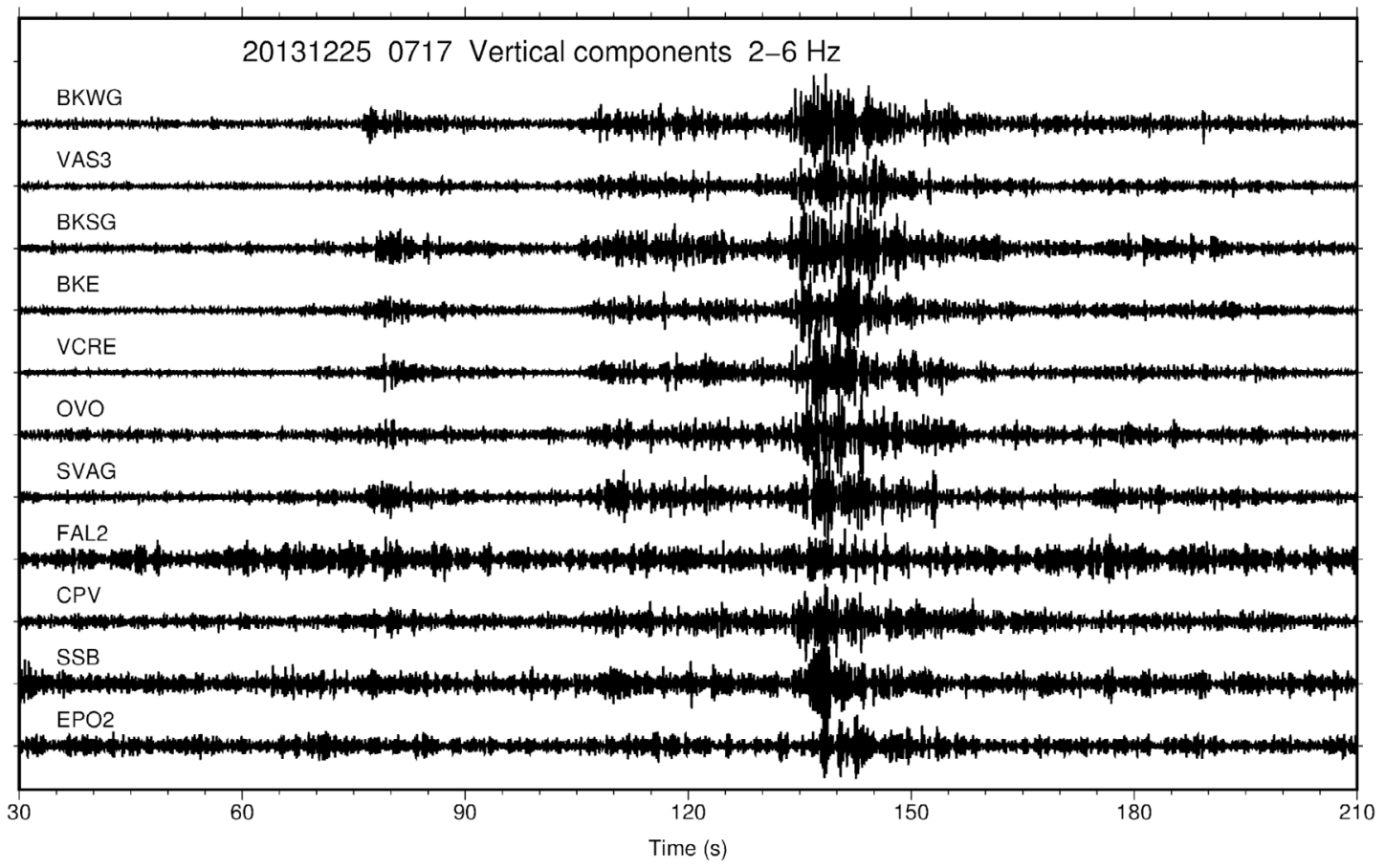

Figure 13. The volcanic tremor shown in Figure 12 as recorded by many of the seismic stations installed on Mt. Vesuvius. Vertical component seismograms, bandpass filtered between $2 \mathrm{~Hz}$ and $6 \mathrm{~Hz}$, are shown with epicentral distance increasing from top to bottom.

bandpass filtered between $2 \mathrm{~Hz}$ and $4 \mathrm{~Hz}$ ), backazimuth and slowness obtained by the BF and HR analysis focused at $3 \mathrm{~Hz}$. This tremor, recorded on December 25, 2013, has a duration of about two minutes, emergent onset and irregular amplitude. Array analysis indicates at least four bursts of energy reaching the array with very small slowness, as evidenced in the plots of Figure 12 by bold blue (BF) and magenta (HR) symbols. Values of slowness between $0.1 \mathrm{~s} / \mathrm{km}$ and $0.4 \mathrm{~s} / \mathrm{km}$, corresponding to apparent velocity between $2.5 \mathrm{~km} / \mathrm{s}$ and $10 \mathrm{~km} / \mathrm{s}$, indicate that the tremor signal contains many body waves reaching the array with a small incidence angle, which means that the source is not shallow. Figure 13 shows a broader view of the tremor signal, as recorded by eleven stations of the local network all around and above the volcano (Figure 2). The relative amplitude at the stations of the local network indicates that the source of this signal is located below the volcano, roughly beneath the crater. Estimating the source depth is very difficult because recognizing $\mathrm{P}$ and $\mathrm{S}$ direct waves is not possible. However, the relative amplitude recorded at different distances suggests a depth similar to the LF earthquake previously discussed and shown in Figure 11. Regarding the source mechanism of this tremor, we do not have many indications from the available data. Spectral content is rich of low frequency, very similar to LF earthquakes, while signs of resonating source, such as a fundamental frequency and its multiples, are not present in the spectra. More tremor events are necessary to address any questions regarding their source process.

\section{Discussion and conclusions}

An efficient monitoring of seismic activity in volcanic areas like Campi Flegrei and Mt. Vesuvius, characterized by high population density, is a difficult task for several reasons. The background noise much higher than remote volcanoes and a lot of transient signals produced by artificial sources complicate considerably the job of seismologists. The case of Campi Flegrei is particularly critical because finding sites appropriate for seismic installations in town is not easy, and because a large part of the active caldera lays below the sea. While signals produced by chemical explosions and transients produced by heavy vehicles and trains are easily recognized, many other signals of different artificial origin are much more difficult to be recognized and classified. Every year we observe tens of signals visible at many stations of the network, coherent at the array, but characterized by emergent onset and low SNR, so that their location and classification often remain uncertain. Important clues on the nature of small signals like LF earthquakes and tremor events come from the array analysis. In fact the estimated slowness of coherent signals permits to distinguish between surface and body waves. Signals propagating as surface waves are likely produced by artificial sources at the ground level, or sometimes in the atmosphere, while signals recorded at the array with high apparent velocity are likely representative of endogenous sources. From the analysis of array data we discovered the volcanic tremor of January 30, 2015, at Campi Flegrei and some short bursts of volcanic 
tremor at Mt. Vesuvius. This is the most important results obtained by the analysis of years of data. In fact at both volcanoes volcanic tremor had never been recorded by modern instruments before the installation of ARF and VAS arrays. The capability to recognize volcanic tremor signals is very important because it is one of the most common precursor phenomena of eruptions, and a marker of the volcano dynamics. The tremor observed in Campi Flegrei on January 30, 2015 , is the first and unique event of this kind ever observed in the area. The very likely hydrothermal origin of this tremor makes it a harmless phenomenon because it is not related with magma dynamics inside the volcano. Nonetheless its observation is important as a reference event for the future monitoring of the volcano. The comparison of rms computed at many stations of the network allowed for the identification of many small LF earthquakes that were neither visible in the unfiltered signals nor found by automatic detection algorithms. On the contrary, we have not seen any LP earthquakes after the swarm occurred in 2006. At present the detection of $\operatorname{LP}(\mathrm{f}<1 \mathrm{~Hz}), \operatorname{VLP}(\mathrm{f}<0.1$ $\mathrm{Hz})$ and ULP $(\mathrm{f}<0.01 \mathrm{~Hz})$ in Campi Flegrei area is a challenging task because the background signals are full of transients even at such low frequency, the most of which are produced by artificial sources.

The few bursts of volcanic tremor identified at Mt. Vesuvius are located at depth of at least $4.5 \mathrm{~km}$ bsl, perhaps even $6 \mathrm{~km}$. Available data do not allow for a comprehensive study of the source of such signals that remains unknown. Although a lot of work remains to do for a better location and characterization of the source of such signals, our present findings add an important information about the current seismicity of Mt. Vesuvius.

The results described in this paper demonstrate the usefulness of seismic arrays in the monitoring of active volcanoes, and suggest that more stations of high quality are necessary for a further improvement of the monitoring capability with the aim of reducing the volcanic risk. Considerations about the technical features of modern instruments suggest that a comprehensive monitoring system is more efficient if composed of different kinds of sensors, including short period, broad band seismometers, and accelerometers.

Acknowledgements. The installation of the stations described in this paper has been possible thank to the collaboration of many people and local institutions that provided a place in their property, and in some cases even the electricity. Most of figures were drawn by GMT [Wessel and Smith 1998]. Suggestions from anonymous reviewers improved the quality of the paper. The projects "PON a3_00278 Vulcamed" and "PON 03PE_00155_1 Optofer" provided funding to purchase some of the used instruments.

\section{Data availability}

Data recorded by the stand-alone seismic network described in this paper are available upon request to the authors.

\section{References}

Capon J. (1969). High-resolution frequency-wavenumber spectrum analysis, Proc. IEEE, 57 (8), 14081418.

Castellano, M., C. Buonocunto, M. Capello and M. La Rocca (2002). Seismic surveillance of active volcanoes: the Osservatorio Vesuviano Seismic Network (OVSN - Southern Italy), Seismol. Res. Lett., 73 (2), 168-175.

Chouet, B.A. (1996). Long-period volcano seismicity: its source and use in eruption forecasting, Nature, 380, 309-316.

Chouet, B.A. (2003). Volcano seismology, Pure Appl. Geophys., 160, 739-788.

Chouet, B.A., and R.S. Matoza (2013). A multi-decadal view of seismic methods for detecting precursors of magma movement and eruption, J. Volc. Geoth. Res., 252, 108-175.

Cusano, P., S. Petrosino and G. Saccorotti (2008). Hydrothermal origin for sustained Long-Period (LP) activity at Campi Flegrei Volcanic Complex, Italy, J. Volc. Geoth. Res., 177, 1035-1044; doi:10.1016/j.j volgeores.2008.07.019.

Cusano, P., S. Petrosino, F. Bianco and E. Del Pezzo (2013). The first Long Period earthquake detected in the background seismicity at Mt. Vesuvius, Annals of Geophysics, 56 (4), S0440; doi:10.4401/ag6447.

D’Auria, L., A.M. Esposito, D. Lo Bascio, P. Ricciolino, F. Giudicepietro, M. Martini, T. Caputo, W. De Cesare, M. Orazi, R. Peluso, G. Scarpato, C. Buonocunto, M. Capello and A. Caputo (2013). The recent seismicity of Mt. Vesuvius: inference on seismogenic processes, Annals of Geophysics, 56 (4), S0442; doi:10.4401/ag-6448.

Del Pezzo, E., F. Bianco, M. Castellano, P. Cusano, D. Galluzzo, M. La Rocca and S. Petrosino (2013). Detection of seismic signals from background noise in the area of Campi Flegrei: limits of the present seismic monitoring. Seismol. Res. Lett., 84 (2), 190-198; doi: $10.1785 / 0220120062$.

Galluzzo, D., E. Del Pezzo, M. La Rocca, M. Castellano and F. Bianco (2009). Source Scaling and Site effects at Vesuvius Volcano, B. Seismol. Soc. Am., 99 (3), 1705-1719.

Galluzzo, D., F. Bianco, M. La Rocca and G. Zonno (2015). Ground motion observations and simulation for local earthquakes in the Campi Flegrei volcanic 
area, B. Earthq. Eng., 1-14; doi:10.1007/s10518-0159770-x.

Goldstein, P., D. Dodge, M. Firpo and L. Minner (2003). SAC2000: Signal processing and analysis tools for seismologists and engineers, Invited contribution to "The IASPEI International Handbook of Earthquake and Engineering Seismology”, Edited by W.H.K. Lee, H. Kanamori, P.C. Jennings and C. Kisslinger, Academic Press, London.

Goldstein, P., and A. Snoke (2005). SAC Availability for the IRIS Community, Incorporated Institutions for Seismology Data Management Center Electronic Newsletter.

Havskov, J., and G. Alguacil (2004). Instrumentation in earthquake seismology, Springer, 360 p.; ISBN: 14020-2968-3.

Konstantinou, K.I., and V. Schlindwein (2002). Nature, wavefield properties and source mechanism of volcanic tremor: a review, J. Volc. Geoth. Res., 119, 161187.

La Rocca, M., and D. Galluzzo (2012). A seismic array in the town of Pozzuoli in Campi Flegrei (Italy), Seismol. Res. Lett., 83 (1), 86-96.

La Rocca, M., and D. Galluzzo (2014). Seismic monitoring of Mt. Vesuvius by array methods, Seismol. Res. Lett., 85 (4), 809-816; doi:10.1785 / 0220130216.

McNutt, S.R. (2005). Volcanic seismology, Annu. Rev. Earth Planet. Sci., 32, 461-491.

Neidell, N.S., and M.T. Taner (1971). Semblance and other coherency measures for multichannel data, Geophysics, 36 (3), 482-497.

Orazi, M., L. D’Auria, A. Tramelli, C. Buonocunto, M. Capello, A. Caputo, W. De Cesare, F. Giudicepietro, M. Martini, R. Peluso and G. Scarpato (2013). The seismic monitoring network of Mt. Vesuvius, Annals of Geophysics, 56 (4), S0450.

Peterson, J. (1993). Observations and modeling of seismic background noise, Open-File Report 93-322, U.S.G.S., Albuquerque, New Mexico.

Rost, S., and C. Thomas (2002). Array seismology: methods and applications, Review of Geophysics, 40 (3), 2.1-2.27.

Rost, S., and C. Thomas (2009). Improving seismic resolution through array processing techniques, Surv. Geophys., 30, 271-299; doi:10.1007/s10712-0099070-6.

Saccorotti, G., S. Petrosino, F. Bianco, M. Castellano, D. Galluzzo, M. La Rocca, E. Del Pezzo, L. Zaccarelli and P. Cusano (2007). Seismicity associated with the 2004-2006 renewed ground uplift at Campi Flegrei caldera, Italy, Phys. Earth Plan. Int., 165, 14-24; doi:10.1016/j.pepi.2007.07.006.

Tramelli, A., D. Galluzzo, E. Del Pezzo and M.A. Di
Vito (2010). A detailed study of the Site Effects at the volcanic area of Campi Flegrei using empirical approaches, Geophys. J. Int., 182 (2), 1073-1086.

Wessel, P., and W.H.F. Smith (1998). New, improved version of the Generic Mapping Tools released, EOS Trans AGU, 79, 579.

Zahradnik, J., and A. Plesinger (2005). Long-Period Pulses in Broadband Records of Near Earthquakes, B. Seismol. Soc. Am., 95 (5), 1928-1939; doi:10.1785/ 0120040210.

Zahradnik, J., and A. Plesinger (2010). Toward Understanding Subtle Instrumentation Effects Associated with Weak Seismic Events in the Near Field, B. Seismol. Soc. Am., 100 (1), 59-73; doi:10.1785/0120090 087.

Corresponding author: Mario La Rocca, Istituto Nazionale di Geofisica e Vulcanologia, Sezione di Napoli, Osservatorio Vesuviano, Naples, Italy; email: mario.larocca@ingv.it.

(C) 2015 by the Istituto Nazionale di Geofisica e Vulcanologia. All rights reserved. 